\title{
Children's self-reports of pain intensity: Scale selection, limitations and interpretation
}

\author{
Carl L von Baeyer PhD RDPsych
}

\begin{abstract}
CL von Baeyer. Children's self-reports of pain intensity: Scale selection, limitations and interpretation. Pain Res Manage 2006;11(3):157-162.

Most children aged five years and older can provide meaningful selfreports of pain intensity if they are provided with age-appropriate tools and training. Self-reports of pain intensity are an oversimplification of the complexity of the experience of pain, but one that is necessary to evaluate and titrate pain-relieving treatments. There are many sources of bias and error in self-reports of pain, so ratings need to be interpreted in light of information from other sources such as direct observation of behaviour, knowledge of the circumstances of the pain and parents' reports. The pain intensity scales most commonly used with children - faces scales, numerical rating scales, visual analogue scales and others - are briefly introduced. The selection, limitations and interpretation of self-report scales are discussed.
\end{abstract}

Key Words: Child; Measurement; Pain intensity; Pain scale; Self-report

\section{Les autoévaluations d'intensité de la douleur par les enfants : la sélection des échelles, leurs limites et leur interprétation}

\begin{abstract}
À partir de cinq ans, la plupart des enfants peuvent fournir une autoévaluation valable de l'intensité de leur douleur si on leur fournit des outils et des explications adaptés à leur âge. Les autoévaluations de l'intensité de la douleur sont une sursimplification de la complexité de l'expérience de la douleur, mais elles s'imposent pour évaluer et titrer les traitements analgésiques. Il existe de nombreuses sources de biais et d'erreurs dans les autoévaluations de la douleur, et c'est pourquoi elles doivent être interprétées à la lumière de l'information tirée d'autres provenances, telles que l'observation directe du comportement, des connaissances et des circonstances de la douleur ainsi que le compte rendu des parents. Les échelles d'intensité de la douleur les plus utilisées chez les enfants, soit les échelles des visages, les échelles d'évaluation numérique, les échelles visuelles analogiques et d'autres, sont présentées brièvement. La sélection, les limites et l'interprétation des échelles d'autoévaluation sont présentées.
\end{abstract}

\section{NEITHER A WASTE OF TIME NOR A GOLD STANDARD}

A tough audience of pediatric anaesthesiologists recently told me, "We don't need to measure pain - we cure it." In their view, using pain scales with children is a waste of time. On the other hand, there has recently been a campaign to promote subjective pain scores as a 'gold standard' or as the 'fifth vital sign' $(1,2)$.

Both of these polarized views are probably overstated. Subjective reports of pain often work extremely well in capturing qualities of experience, but it is necessary to recognize that they are subject to personal response biases, reflect the person's appraisal of the consequences of the pain report and require certain cognitive skills $(3,4)$. Self-report pain scores are not vital (essential for life), a sign (objective physical finding) or a gold standard (a criterion against which other measures should be judged). However, it has been shown that regular pain measurement improves pain management $(5,6)$. Children's self-reports of pain intensity are a valuable source of information, but their interpretation must be considered together with observation of behaviour, reports by parents, clinical data and information on the child's social environment (7-9). Estimates of pain intensity based on these other sources may not always correlate highly with children's self-report of pain (10), and may reflect different perspectives of the pain experience (11).

The following brief review addresses the main practical issues in selection of age-appropriate self-report tools and the interpretation of self-report pain intensity scores. A more specific systematic review of self-report measures has recently been completed; it recommends a set of outcome measures of pain severity for pediatric clinical trials (12).

\section{A NECESSARY OVERSIMPLIFICATION}

Pain is highly complex and multidimensional. Describing pain only in terms of its intensity is like describing music only in terms of its loudness. Pain intensity scores are inherently an oversimplification because they neglect features such as the location, sensory quality, and affective and cognitive aspects of the experience of pain. However, pain intensity scores serve a very useful purpose in sensitively evaluating the effects of painrelieving and pain-producing interventions (13). Thus, pain intensity scores can be seen as a necessary oversimplification.

Comparisons of different pain-producing and pain-relieving conditions can be conducted across time within persons, or across groups of patients. Because pain treatment may be effective without eliminating all pain, a simple dichotomous estimation (pain/no pain) is not adequate to capture such effects; a graded scale is needed. Pain intensity scores constitute a core outcome domain in randomized, controlled trials of painrelieving treatments (14).

\section{PAIN SCALES FOR CHILDREN}

The principal types of scales that have been used to measure pain intensity in children are listed in Table 1. 
TABLE 1

Types of pain scales used with children

\begin{tabular}{lcc}
\hline Type of scale (references) & $\begin{array}{c}\text { Approximate } \\
\text { minimum } \\
\text { age (years) }\end{array}$ & $\begin{array}{c}\text { Pediatric validation } \\
\text { research to date }\end{array}$ \\
\hline Adjective scales $(28)$ & 9 & Minimal or none \\
Numerical rating scales $(56-58)$ & 8 & Minimal or none \\
Visual analogue scales $(26,27,59)$ & 6 & Extensive \\
Faces scales $(18-20,39,60)$ & 4 & Extensive \\
Colour scales $(61,62)$ & $4 ?$ & Minimal or none \\
Pieces of Hurt $(29)$ & 3 & Some \\
\hline
\end{tabular}

Note: Not all children at the suggested minimum age will be able to make valid use of the scale. As many as three-quarters of normally developing threeyear-olds may not understand a graded self-report task even with an ageappropriate tool

\section{Numerical rating scales}

Numerical rating scales (NRS) (15) involve asking for estimates of pain using numbers representing increasing pain severity. Such scales, particularly the NRS-11 (which is scored 0 to 10), have not been adequately tested in research with child participants; nevertheless, they are the scales most frequently used for children older than eight years of age because they have the advantage of requiring no equipment (and perhaps because they are commonly used with adults). They do, however, require numeracy, the ability to think and express oneself in quantitative terms, and verbal communication skills. Young children may provide numbers on an NRS that are idiosyncratic and unreliable because, although they may be able to count, they have not yet developed an understanding of the quantitative significance of numbers $(16,17)$.

\section{Faces scales}

Faces scales require selecting a picture of a face that represents one's pain intensity (Figure 1). They fall into two categories: drawings $(18,19)$ and photographs $(20)$. An advantage of the drawings is that they can be readily and inexpensively reproduced by black and white photocopying. The drawings lack specific ethnic or gender features, so they may be applicable to broader demographic groups than the photographic scales which portray real boys and girls of selected ethnic groups. Faces scales may not require the ability to seriate or estimate quantities, because the task can be handled by simply matching how one feels to one of the faces, which is presumed to be easier than quantitative estimation (21). Generally, children prefer faces scales to visual analogue scales (VAS) when given a choice (22-24).

\section{VAS}

VAS require selecting a point on a line representing the dimension of pain intensity. They have been extensively researched and they show good sensitivity and validity for most children at age seven years and older $(25,26)$. The Coloured Analogue Scale (27) (Table 2) is a VAS that uses a mechanical slider to indicate pain intensity. It has been particularly well investigated, but unlike some other scales it requires the purchase and possible sterilization of a plastic tool. Paper-based VAS require an extra step in measuring the line.

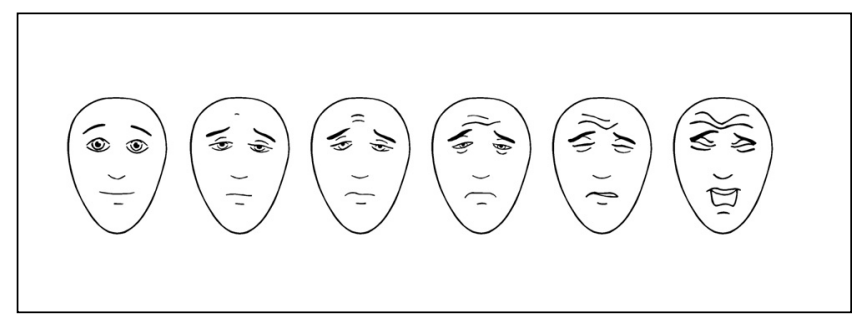

Figure 1) The Faces Pain Scale-Revised (18). Scored 0, 2, 4, 6, 8 and 10. Available with instructions in many languages at $<w w w$.painsourcebook.ca>. Reprinted with permission. (C) 2001 International Association for the Study of Pain

TABLE 2

\begin{tabular}{|c|c|}
\hline $\begin{array}{l}\text { Recommended } \\
\text { age range (years) }\end{array}$ & Scale \\
\hline 9 to adult & $\begin{array}{l}\text { Numerical Rating Scale: "Please tell me how much it } \\
\text { hurts using a number from } 0 \text { to } 10 \text {. Zero means no } \\
\text { pain and } 10 \text { is the most pain." Most convenient } \\
\text { tool because it requires no equipment, but it is not } \\
\text { well researched with children. }\end{array}$ \\
\hline 5 to 17 & Coloured Analogue Scale $(27)^{\star}$ \\
\hline 4 to 12 & Faces Pain Scale - Revised $(18)^{\dagger}$ \\
\hline 3 to 6 & Pieces of Hurt $(29,63)^{\ddagger}$ \\
\hline
\end{tabular}

Adjective scales

Adjective scales involve selecting a word out of a set of descriptors of pain intensity (28). These scales require verbal fluency at a high school level and have not been investigated extensively with children.

\section{Pieces of Hurt}

The Pieces of Hurt tool (also known as Poker Chip Tool) (29) quantifies pain intensity by using four poker chips to represent amounts of pain. Children indicate how much hurt they have by referring to one poker chip as a little bit of hurt, two as a little more hurt, three as more yet, and four as the most hurt they could ever have. The Pieces of Hurt tool has been used as a comparison tool to support the criterion validity of other pain tools, such as the pain ladder and the VAS $(30,31)$.

\section{Colour scales}

The colour scales (unlike the Coloured Analogue Scale, which is a VAS) require the child to select crayons and draw colours matching different levels of pain severity. Very little research has been done with the colour scales. They take more time to administer than any of the other scales and are now rarely seen in clinical use.

\section{AGE AND ABILITY TO SELF-REPORT PAIN}

The approximate proportions of children at different ages who are able to provide self-reports of pain, given that they have been trained in the use of an age-appropriate tool, are shown in Figure 2. 


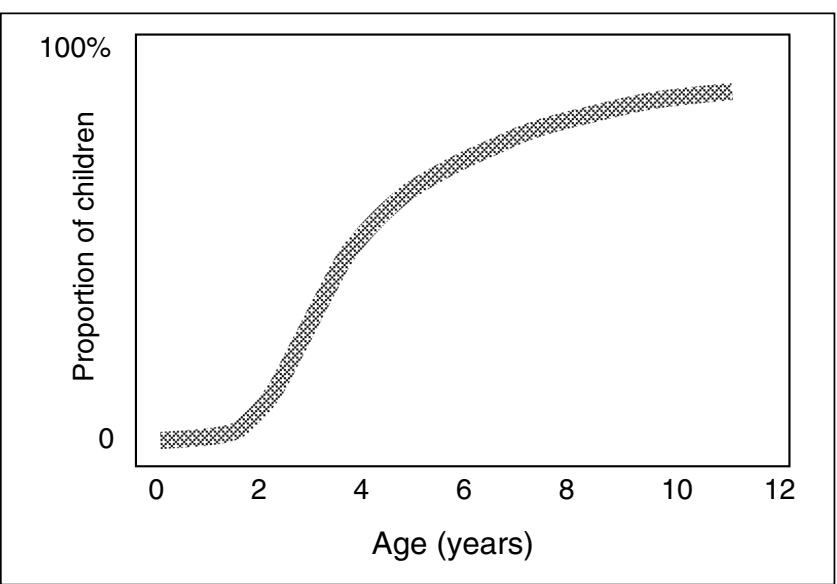

Figure 2) An estimate of the proportion of children at different ages who are able to provide reliable self-report of pain when given an ageappropriate scale under optimal conditions. (C) CL von Baeyer, 2004

A pain scale designed for children should ideally have many or all of the features identified in Table 3. Among these features, a strong evidence base is particularly important. Indications that children are able to apply a pain scale in a consistent (reliable) and valid way come from the following five lines of evidence. The references provide examples.

1. Correlations of pain self-report ratings with other validated self-report and observational pain scales administered at the same time $(18,27)$.

2. Accurate ranking of hypothetical no pain, moderatepain, and high-pain events presented in pictures or stories (32).

3. Increased pain ratings in response to painful clinical or experimental procedures (33).

4. Decreased pain ratings in response to analgesic interventions or less painful ways of performing a procedure $(34,35)$.

5. Decreased pain ratings over successive days or hours of postoperative or postinjury recovery $(36,37)$.

\section{ANCHOR EFFECTS}

The term 'anchor effect' refers to the influence of surrounding conditions or prior experience on the estimation of a quantity. For example, a $50 \mathrm{~g}$ weight feels heavier after holding a $10 \mathrm{~g}$ weight than it does after holding a $100 \mathrm{~g}$ weight. The anchors that are verbally described on most pain scales are at the lower end of the scale, representing no pain, and at the upper end of the scale, representing some theoretical maximum. Pain ratings on faces scales are influenced by whether the lower anchor face is smiling or not $(38,39)$. There has been little research into what children think of when they are told that the upper end of the scale represents "the worst pain you can imagine", or "the biggest hurt". Although some scales provide a top anchor such as "worst possible pain", this is considered difficult for young children because it requires an understanding of the abstract concept of possibility (16). A child who thinks of the worst possible

\section{TABLE 3}

Desirable features of a pain scale

Reasonably valid and reliable, as established by research

Developmentally and culturally appropriate to patients (ie, within the child's cognitive and language skills)

Easily and quickly understood by patients who have minimal formal education Well-liked by patients and clinicians

Quickly and easily explainable to patients

Easily used with the patient to set pain management goals or comfort-function goals

Places low burden on clinician (ie, quick and easy to score and record)

Inexpensive and easy to obtain, reproduce and distribute to clinicians, patients and their families

Readily available (eg, on the Internet)

Easily disinfected (or in the case of photocopied scales, inexpensive enough to discard after use)

Available with instructions in various languages

Adapted from references 64 and 65

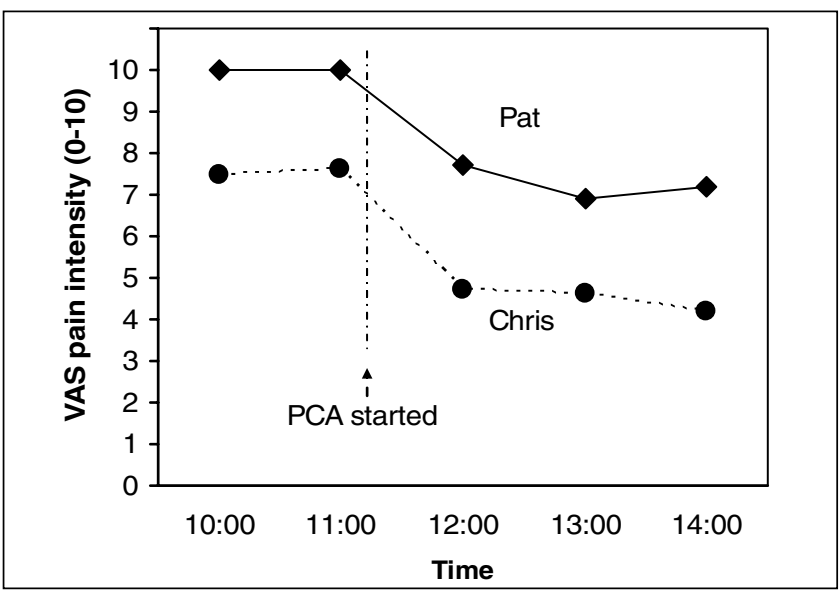

Figure 3) Pain trajectories for two hypothetical postsurgical patients. One cannot conclude that Pat is experiencing more pain than Chris, but the analgesics appear to be helping both patients. PCA Patientcontrolled analgesia; VAS Visual analogue scale. (C) CL von Baeyer, 2006

pain as the needle that he is experiencing at that moment may give a higher rating than another child who is concurrently aware of other, much more severe, forms of pain.

\section{INTRAINDIVIDUAL VERSUS INTERINDIVIDUAL COMPARISONS}

Figure 3 shows the pain trajectories (on a VAS) over time for two hypothetical postsurgical patients. One cannot conclude that Pat necessarily is experiencing more pain than Chris, because one cannot assume that they are construing the pain scales, and specifically the anchors, in the same way. However, the analgesic appears to be relieving pain to some extent in both cases; thus, these intraindividual comparisons provide guidance for continuation and adjustment of the treatment. 


\section{PAIN RATINGS IN PRESCHOOL-AGE CHILDREN}

Special considerations apply to children of preschool age. Young children who have not yet experienced school are not used to being asked questions by strangers. They are also not experienced in giving quantitative ratings or estimates. Questions such as “Are you tired?" or "Are you hungry?" are generally treated as yes or no questions by people caring for children; graded estimates of such internal states are rarely requested. The language used in asking young children about pain must be kept simple; for example, children do not spontaneously use the word 'pain' before age six although they use the word 'hurt' from age 2.5 years (40).

Moreover, it has been shown that young children who do not understand a question will often construct an answer anyway, based on their current understanding of the situation. Many children younger than five years of age have a marked tendency to use only the extremes of scales; in other words, they treat the scale as dichotomous rather than graded (41). Other response sets or biases include giving the same answer to all questions, and responding in an upward or downward sequence to successive questions (eg, pointing to faces scaled 0,2, 4, 6 and 8). Recent studies (42) revealed that these response biases can be detected in up to threequarters of three-year-olds in response to pain rating questions. A child's lack of understanding of the request for a pain rating may not become evident on the basis of a single rating, because these response sets may be detected only with repeated questions.

Children's self-reports of pain may be affected by their perception of the consequences of the rating. If a child thinks that she is going to get an extra needle after reporting pain, then she is likely to suppress or minimize her report. On the other hand, if the report of pain has desirable consequences, such as being allowed to stay home from school if the pain is severe, then higher self-ratings may be given. Many other cognitive, social and cultural factors influence pain ratings (eg, previous painful experiences, temperament, presence of an audience, family and community norms for pain expression), making them idiosyncratic and difficult to interpret $(43-45)$.

\section{THE MINIMUM CLINICALLY SIGNIFICANT DIFFERENCE AND THE PAIN TREATMENT THRESHOLD}

A few studies $(37,46)$ have addressed the question of how large a difference in pain scores is clinically significant. If a child's pain diminishes from 8 to 7 following intervention, does that represent a success in treatment? Estimates of the minimum clinically significant difference depend on the type of pain, the starting pain level and other factors, but they tend to be in the $10 \%$ to $20 \%$ range. In other words, a change of one face on the Faces Pain Scale - Revised, or a change of $10 \mathrm{~mm}$ to $20 \mathrm{~mm}$ on a $100 \mathrm{~mm}$ VAS, would be the smallest meaningful change $(37,46)$.

The pain treatment threshold (formerly termed 'drug request point' [47]) provides another ipsative (self-referenced) standard against which to compare self-report scores. The pain treatment threshold is the pain score above which a patient would want analgesia. Many children report pain worse than their pain treatment threshold during postoperative recovery (48), indicating that their pain is poorly managed.

\section{SELECTING, ADMINISTERING AND INTERPRETING A PAIN SCALE}

Here are some practical points of advice concerning assessment of children's pain using self-report scales.

1. Pick a tool appropriate for the child's age (Table 1) that has as many desirable features as possible (Table 3). A selection of four self-report scales covering the pediatric age range is shown in Table 2.

2. If possible, introduce the child to the scale when he or she is not in pain, because it will be more difficult to explain the tool if the child's concentration is impaired.

3. With very young children, and with those who are unable to understand the self-report task due to cognitive impairment or high levels of distress, use observational measures $(8,49-52)$.

4. Offer the child a chance to practice with the scale by rating hypothetical situations that would produce low and high levels of pain, eg, opening a birthday present versus stepping on a sharp nail.

5. When possible, obtain successive pain ratings over time, and observe their covariation with pain-relieving interventions as well as with events known to increase pain, such as needles.

6. Obtaining pain scores should not be seen as a substitute for talking with patients. Their narrative should always be obtained to provide context for the pain scores.

7. Take charted pain scores into account when planning treatment.

8. When discrepancies arise among pain scores provided by the child, parent and clinician, these differences can often be resolved through discussion, so that pain management can be guided by the best estimate of the pain severity.

Measurement of children's pain by self-report has previously been reviewed (12,53-55) and the reader is encouraged to access more detail through these publications. The present brief review has been limited to self-reports of pain intensity, and has not covered other important aspects of pain management. For example, a child may prefer to accept a moderate degree of pain if it means having a mind unclouded by strong opioids. Other dimensions of the pain experience, such as its affective impact (distress and fear), the way it is cognitively construed and dealt with (catastrophizing, perceived control and coping), and the functional disability it produces (reduced activity and missing school), all should be assessed along with pain intensity. However, formal psychometric methods for measuring these other variables are more complex and less well known than the simple unidimensional pain intensity scales.

\section{SUMMARY}

Self-report measures have often been underutilized in assessing children's pain. They can be used in conjunction with observer reports of pain and can provide a valuable indication of treatment outcome in both clinical and research contexts. Pain management is improved when pain is regularly and reliably 
measured $(5,6)$. Tools designed for children's self-report of pain, such as those listed in Table 2, do require more research, but can provide effective guidance for pain management practice.

ACKNOWLEDGEMENTS: The author thanks the following (in alphabetic order) for their comments on an earlier version of this article: L Besenski, CT Chambers, KD Craig, SJ Forsyth, M-C Grégoire, CC Johnston, Ó Kristjánsdóttir, D Lake, T Marche, PJ McGrath, T Piira, S Rhyno, J Skakun and F Visram. Opinions expressed and any errors should be attributed solely to the author.

\section{REFERENCES}

1. Campbell J. American Pain Society: Advocacy \& Policy. Pain: The Fifth Vital Sign. 2006. <www.ampainsoc.org/advocacy/fifth.htm> (Version current at July 17, 2006).

2. Jackson M. Pain: The Fifth Vital Sign. New York: Crown, 2002.

3. Craig KD, Lilley CM, Gilbert CA. Social barriers to optimal pain management in infants and children. Clin J Pain 1996;12:232-42.

4. Craig K. Giamberardino M, ed. Pain 2002 - An updated review. Refresher Course Syllabus. Pain in infants and children: Sociodevelopmental variations on a theme. 10th World Congress on Pain. San Diego: IASP Press, 2002.

5. Franck LS, Greenberg CS, Stevens B. Pain assessment in infants and children. Pediatr Clin North Am 2000;47:487-512.

6. Treadwell MJ, Franck LS, Vichinsky E. Using quality improvement strategies to enhance pediatric pain assessment. Int J Qual Health Care 2002;14:39-47.

7. Craig K. The facial display of pain. In: Finley G, McGrath P, eds. Measurement of Pain in Infants and Children. Seattle: IASP Press, 1998:103-21.

8. McGrath P. Behavioral measures of pain. In: Finley G, McGrath P, eds. Measurement of Pain in Infants and Children. Seattle: IASP Press, 1998:83-101.

9. Craig KD, Badali MA. Introduction to the special series on pain deception and malingering. Clin J Pain 2004;20:377-82.

10. Chambers CT, Reid GJ, Craig KD, McGrath PJ, Finley GA. Agreement between child and parent reports of pain. Clin J Pain 1998; 14:336-42.

11. Manne SL, Jacobsen PB, Redd WH. Assessment of acute pediatric pain: Do child self-report, parent ratings, and nurse ratings measure the same phenomenon? Pain 1992;48:45-52.

12. Stinson JN, Kavanagh T, Yamada J, Gill N, Stevens B. Systematic review of the psychometric properties, interpretability and feasibility of self-report pain intensity measures for use in clinical trials in children and adolescents. Pain 2006 [e-pub ahead of print].

13. Gauthier JC, Finley GA, McGrath PJ. Children's self-report of postoperative pain intensity and treatment threshold: Determining the adequacy of medication. Clin J Pain 1998;14:116-20.

14. Dworkin RH, Turk DC, Farrar JT, et al; IMMPACT. Core outcome measures for chronic pain clinical trials: IMMPACT recommendations. Pain 2005;113:9-19.

15. Jensen MP, Karoly P, Braver S. The measurement of clinical pain intensity: A comparison of six methods. Pain 1986;27:117-26.

16. Gaffney A, McGrath P, Dick B. Measuring pain in children: Developmental and instrument issues. In: Schechter N, Berde CB, Yaster M, eds. Pain in Infants, Children and Adolescents, 2nd edn. Philadelphia: Lippincott Williams \& Wilkins, 2003:128-41.

17. Gelman R, Meck E. Preschoolers' counting: Principles before skill. Cognition 1983;13:343-59.

18. Hicks CL, von Baeyer CL, Spafford PA, van Korlaar I, Goodenough B. The Faces Pain Scale - Revised: Toward a common metric in pediatric pain measurement. Pain 2001;93:173-83.

19. Wong DL, Hockenberry-Eaton M, Wilson D, Winkelstein M, Schwartz P. Whaley and Wong's Essentials of Pediatric Nursing, 5th edn. St Louis: Mosby, 2001.

20. Beyer JE, Denyes MJ, Villarruel AM. The creation, validation, and continuing development of the Oucher: A measure of pain intensity in children. J Pediatr Nurs 1992;7:335-46.

21. Champion GD, Goodenough B, von Baeyer CL, Thomas W. Measurement of pain by self-report. In: Finley GA, McGrath PJ, editors. Measurement of Pain in Infants and Children. Seattle: IASP Press, 1998:123-60.

22. Luffy R, Grove SK. Examining the validity, reliability, and preference of three pediatric pain measurement tools in AfricanAmerican children. Pediatr Nurs 2003;29:54-9.

23. De Tovar CR. Auto-évaluation de la douleur postopératoire chez l'enfant: Echelle visuelle analogique (EVA) versus Faces Pain Scale Revised (FPS-R) [Self-assessment of post-operative pain in children: VAS versus FPS-R]. MD Dissertation. Université de Bretagne Occidentale, 2001.

24. Miro J, Huguet A. Evaluation of reliability, validity, and preference for a pediatric pain intensity scale: The Catalan version of the Faces Pain Scale - Revised. Pain 2004;111:59-64.

25. Shields BJ, Cohen DM, Harbeck-Weber C, Powers JD, Smith GA. Pediatric pain measurement using a visual analogue scale: A comparison of two teaching methods. Clin Pediatr (Phila) 2003;42:227-34.

26. Shields BJ, Palermo TM, Powers JD, Grewe SD, Smith GA. Predictors of a child's ability to use a visual analogue scale. Child Care Health Dev 2003;29:281-90.

27. McGrath PA, Seifert CE, Speechley KN, Booth JC, Stitt L, Gibson MC. A new analogue scale for assessing children's pain: An initial validation study. Pain 1996;64:435-43.

28. Tesler MD, Savedra MC, Holzemer WL, Wilkie DJ, Ward JA, Paul SM. The word-graphic rating scale as a measure of children's and adolescents' pain intensity. Res Nurs Health 1991;14:361-71.

29. Hester N, Foster R, Kristensen K. Measurement of pain in children: Generalizability and validity of the Pain Ladder and the Poker Chip Tool. In: Tyler D, Krane E, eds. Pediatric Pain, Vol 15: Advances in Pain Research and Therapy. New York: Raven Press, 1990:79-84.

30. Aradine CR, Beyer JE, Tompkins JM. Children's pain perception before and after analgesia: A study of instrument construct validity and related issues. J Pediatr Nurs 1988;3:11-23.

31. Gharaibeh M, Abu-Saad H. Cultural validation of pediatric pain assessment tools: Jordanian perspective. J Transcult Nurs 2002;13:12-8.

32. Belter R, McIntosh J, Finch A, Saylor C. Preschoolers' ability to differentiate levels of pain: Relative efficacy of three self-report measures. J Clin Child Psychol 1988;17:329-35.

33. Goodenough TB, Perrott DA, Champion GD, Thomas W. Painful pricks and prickle pains: Is there a relation between children's ratings of venipuncture pain and parental assessments of usual reaction to other pains? Clin J Pain 2000;16:135-43.

34. Beyer JE, Knott CB. Construct validity estimation for the AfricanAmerican and Hispanic versions of the Oucher Scale. J Pediatr Nurs 1998;13:20-31.

35. Wood C, von Baeyer CL, Bourrillon A, Dejos-Conant V, Clyti N, Abitbol V. Self-assessment of immediate post-vaccination pain after two different MMR vaccines administered as a second dose in 4- to 6-year-old children. Vaccine 2004;23:127-31.

36. Perrott DA, Goodenough B, Champion GD. Children's ratings of the intensity and unpleasantness of post-operative pain using facial expression scales. Eur J Pain 2004;8:119-27.

37. Powell CV, Kelly AM, Williams A. Determining the minimum clinically significant difference in visual analog pain score for children. Ann Emerg Med 2001;37:28-31.

38. Chambers CT, Craig KD. An intrusive impact of anchors in children's faces pain scales. Pain 1998;78:27-37.

39. Chambers CT, Giesbrecht K, Craig KD, Bennett SM, Huntsman E. A comparison of faces scales for the measurement of pediatric pain: Children's and parents' ratings. Pain 1999;83:25-35.

40. Stanford EA, Chambers CT, Craig KD. A normative analysis of the development of pain-related vocabulary in children. Pain 2005;114:278-84.

41. Chambers CT, Johnston C. Developmental differences in children's use of rating scales. J Pediatr Psychol 2002;27:27-36.

42. von Baeyer CL, Forsyth SJ, Stanford EA, Hayton K, Chambers CT. Response sets and biases in preschool children's use of pain scales: Are they really rating pain? 11th World Congress on Pain, Sydney, Australia. Seattle: IASP Press, 2005

43. Mechanic D. The concept of illness behavior. J Chronic Dis 1962;15:189-94.

44. Craig K, Pillai R. Social influences, culture \& ethnicity. In: Finley GA, McGrath P, eds. The Context of Pediatric Pain: Biology, Family, Society and Culture. Seattle: IASP Press, 2003:159-82. 
45. de C Williams AC, Davies HT, Chadury Y. Simple pain rating scales hide complex idiosyncratic meanings. Pain 2000;85:457-63.

46. Kelly A. Setting the benchmark for research in the management of acute pain in emergency departments. Emerg Med (Fremantle) 2001; 13:57-60.

47. Wolff B. Behavioral measurement of human pain. In: Sternbach R, ed. The Psychology of Pain, 2nd edn. New York: Raven Press, 1986:121-51.

48. Demyttenaere S, Finley GA, Johnston CC, McGrath PJ. Pain treatment thresholds in children after major surgery. Clin J Pain 2001;17:173-7.

49. Breau LM, McGrath PJ, Camfield CS, Finley GA. Psychometric properties of the non-communicating children's pain checklistrevised. Pain 2002;99:349-57.

50. Breau LM, Finley GA, McGrath PJ, Camfield CS. Validation of the Non-communicating Children's Pain Checklist-Postoperative Version. Anethesiology 2002;96:528-35. (Erratum in 2002;97:769.)

51. Breau LM, Camfield C, McGrath PJ, Rosmus C, Finley GA. Measuring pain accurately in children with cognitive impairments: Refinement of a caregiver scale. J Pediatr 2001;138:721-7.

52. Merkel SI, Voepel-Lewis T, Shayevitz JR, Malviya S. The FLACC: A behavioral scale for scoring postoperative pain in young children. Pediatr Nurs 1997;23:293-7.

53. Champion G, Goodenough B, von Baeyer CL, Thomas W. Measurement of pain by self-report. In: Finley G, McGrath P, eds. Measurement of Pain in Infants and Children. Seattle: IASP Press, 1998:123-60.

54. Royal College of Paediatrics and Child Health. Guidelines for Good Practice - Recognition and Assessment of Acute Pain in Children. 2001. <www.rcpch.ac.uk/publications/clinical docs/Acute_pain.pdf $>$ (Version current at July 17, 2006).
55. Royal College of Nursing. The recognition and assessment of acute pain in children - Technical report. 2002. <www.rcn.org.uk/publications/pdf/guidelines/cpg_contents.pdf > (Version current at July 17, 2006).

56. Fanurik D, Koh JL, Harrison RD, Conrad TM, Tomerlin C. Pain assessment in children with cognitive impairment. An exploration of self-report skills. Clin Nurs Res 1998;7:103-19.

57. McCaffery M, Pasero C. Teaching patients to use a numerical painrating scale. Am J Nurs 1999;99:22.

58. Bijur PE, Latimer CT, Gallagher EJ. Validation of a verbally administered numerical rating scale of acute pain for use in the emergency department. Acad Emerg Med 2003;10:390-2.

59. Maunuksela EL, Olkkola KT, Korpela R. Measurement of pain in children with self-reporting and behavioral assessment. Clin Pharmacol Ther 1987;42:137-41.

60. Kuttner L, LePage T. Faces scales for the assessment of pediatric pain: A critical review. Can J Behav Sci 1989;21:198-209.

61. Eland JM. Eland color scale: Directions for use. 1989. <www.painresearch.utah.edu/cancerpain/attachb6.html> (Version current at July 17, 2006).

62. Eland JM. Minimizing pain associated with prekindergarten intramuscular injections. Issues Compr Pediatr Nurs 1981;5:361-72.

63. Hester NK. The preoperational child's reaction to immunization. Nurs Res 1979;28:250-5.

64. Hester N, Foster R, Jordan-Marsh M, Ely E, Vojir C, Miller K. Putting pain measurement into clinical practice. In: Finley G, McGrath P, eds. Measurement of Pain in Infants and Children. Seattle: IASP Press, 1998:179-98.

65. McCaffery M, Pasero C. Pain: Clinical Manual, 2nd edn. St Louis: Mosby, 1999. 


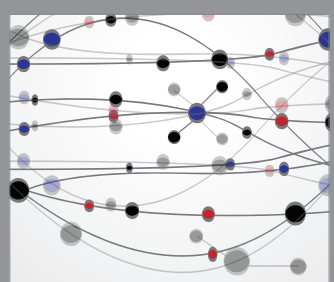

The Scientific World Journal
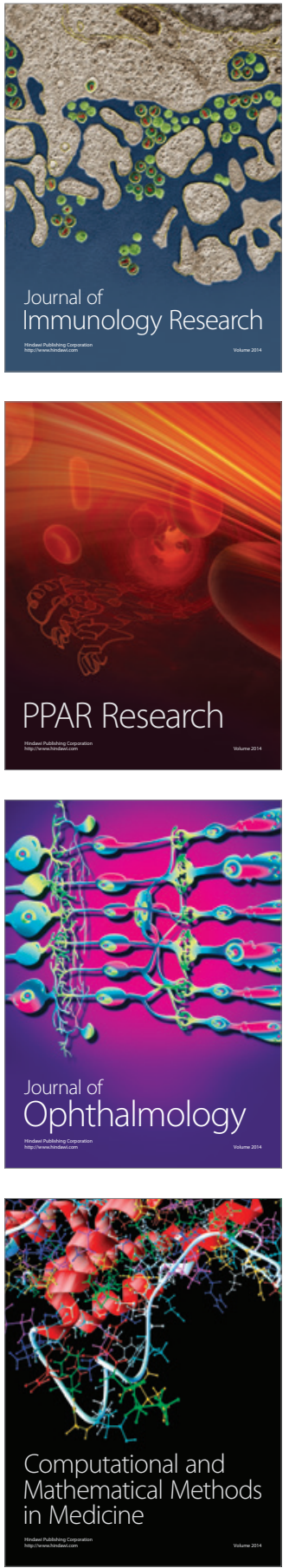

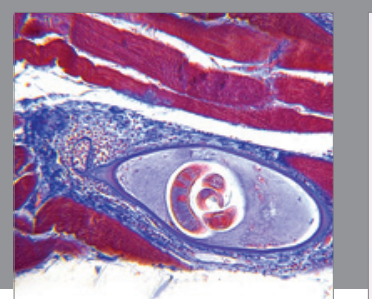

Gastroenterology Research and Practice

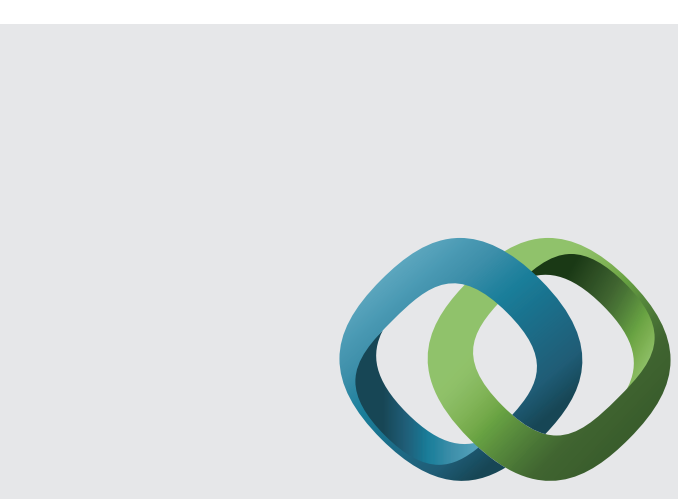

\section{Hindawi}

Submit your manuscripts at

http://www.hindawi.com
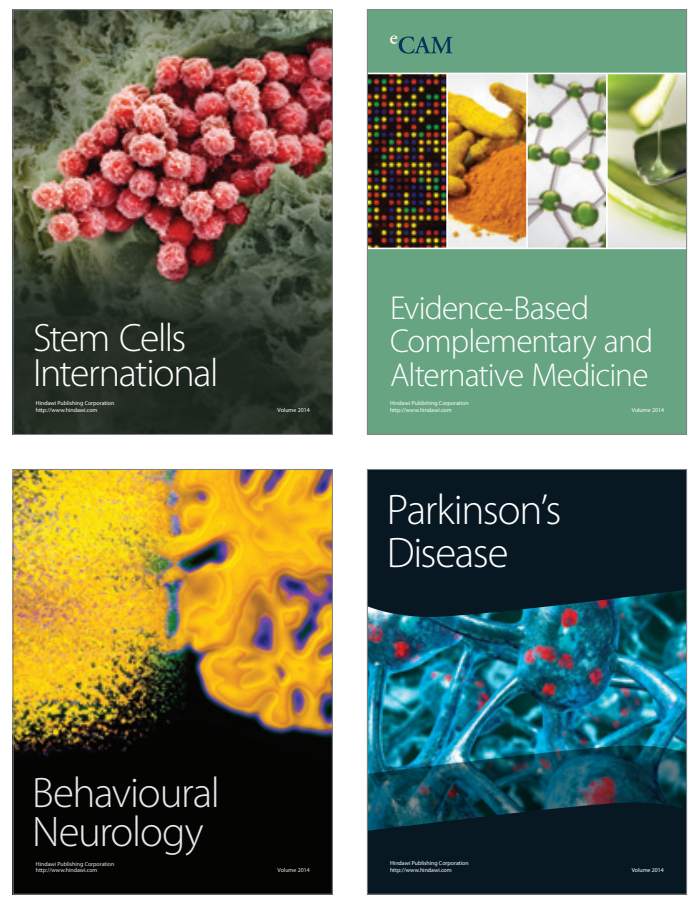
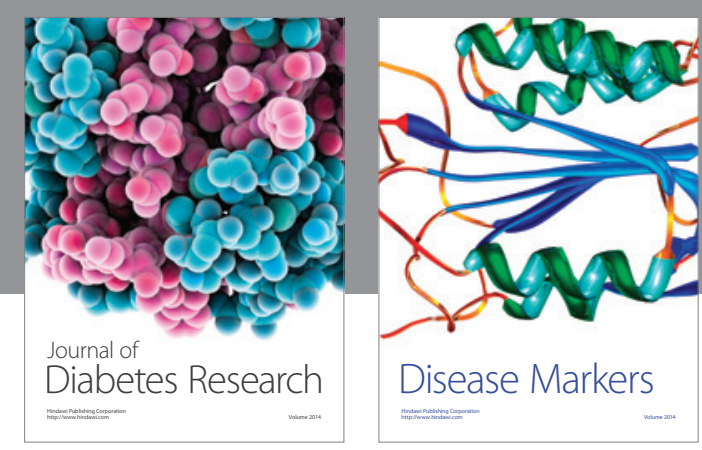

Disease Markers
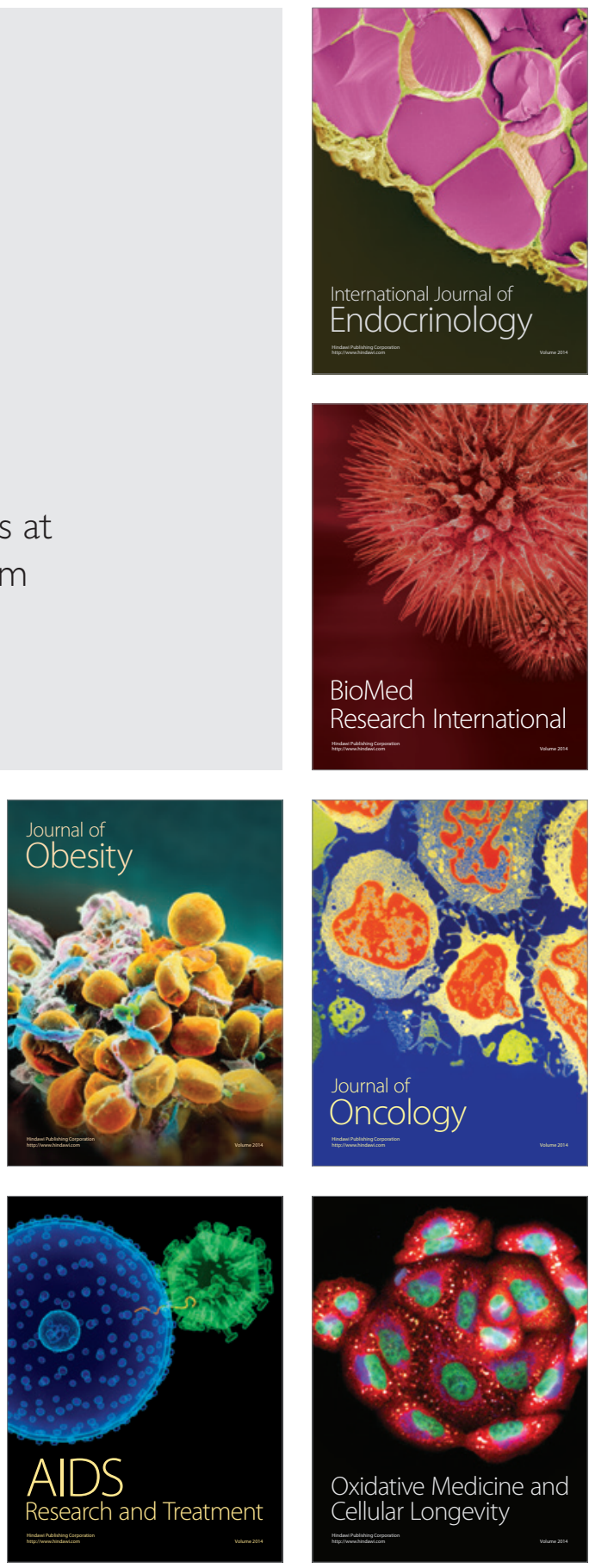